\title{
Hofmeister Effect on PNIPAM in Bulk and at an Interface: Surface Partitioning of Weakly Hydrated Anions
}

\author{
Moghaddam, Saeed Zajforoushan; Thormann, Esben
}

Published in:

Langmuir

Link to article, DOI:

10.1021/acs.langmuir.7b00953

Publication date:

2017

Document Version

Peer reviewed version

Link back to DTU Orbit

Citation (APA):

Moghaddam, S. Z., \& Thormann, E. (2017). Hofmeister Effect on PNIPAM in Bulk and at an Interface: Surface Partitioning of Weakly Hydrated Anions. Langmuir, 33(19), 4806-4815.

https://doi.org/10.1021/acs.langmuir.7b00953

\section{General rights}

Copyright and moral rights for the publications made accessible in the public portal are retained by the authors and/or other copyright owners and it is a condition of accessing publications that users recognise and abide by the legal requirements associated with these rights.

- Users may download and print one copy of any publication from the public portal for the purpose of private study or research.

- You may not further distribute the material or use it for any profit-making activity or commercial gain

- You may freely distribute the URL identifying the publication in the public portal

If you believe that this document breaches copyright please contact us providing details, and we will remove access to the work immediately and investigate your claim. 


\title{
Hofmeister Effect on PNIPAM in Bulk and at an
}

\section{Interface: Surface Partitioning of Weakly}

\author{
Hydrated Anions
}

Saeed Zajforoushan Moghaddam and Esben Thormann*

Department of Chemistry, Technical University of Denmark, 2800 Kgs. Lyngby, Denmark

Keywords: Hofmeister effect, poly(N-isopropylacrylamide), phase separation, surface partitioning, electrostatic stabilization 
Abstract. Effect of sodium fluoride, sodium trichloroacetate, and sodium thiocyanate on the stability and conformation of poly( $N$-isopropylacrylamide), in bulk solution and at the goldaqueous interface, is investigated by differential scanning calorimetry, dynamic light scattering, quartz crystal microbalance, and atomic force microscopy. The results indicate a surface partitioning of the weakly hydrated anions, i.e., thiocyanate and trichloroacetate, and the findings are discussed in terms of anion-induced electrostatic stabilization. Although attractive polymer-ion interactions are suggested for thiocyanate and trichloroacetate, a saltingout effect is found for sodium trichloroacetate. This apparent contradiction is explained by a combination of previously suggested mechanisms for the salting-out effect by weakly hydrated anions. 


\section{INTRODUCTION}

Stimuli-responsive polymers undergo a change in conformation and interaction in response to an external stimulus and are of great importance in numerous areas, such as biomedical engineering and the fabrication of smart surfaces. ${ }^{1,2,3,4}$ Since the earliest report in 1967 , $\operatorname{poly}(N$-isopropylacrylamide) (PNIPAM) has drawn enormous attention because of its abrupt phase transition, which is reminiscent of protein folding and denaturation. ${ }^{5}$ Furthermore, PNIPAM has a phase separation temperature in the proximity of human body temperature, rendering it a promising candidate for drug delivery and other biomedical applications. ${ }^{6,7,8}$ Regarding thermo-responsiveness, PNIPAM shows lower critical solution temperature (LCST) phase behavior, meaning that water miscibility decreases with increasing temperature. ${ }^{9,}, 10,11$ Below the phase separation temperature, PNIPAM adopts a swollen coil conformation, while a drastic decline in hydrophilicity and coil size occurs upon crossing the phase separation boundary.

Presence of ions, particularly anions, can also influence the stability of PNIPAM in aqueous solutions; this effect is widely known as the Hofmeister effect. ${ }^{12,13,14,15}$ This phenomenon not only depends on the ionic strength of the solution, but also relies on other ionic properties, such as size, polarizability, hydration energetics, and the partition coefficient. In other words, it is "ion-specific."16, 17, 18 The Hofmeister effect of anions on uncharged polymers, such as PNIPAM, can be divided into two distinct types: ${ }^{19,20,21,22,23,24}$

(i) Strongly hydrated anions, e.g., fluoride $\left(\mathrm{F}^{-}\right)$, decrease the polymer stability in solution (a "salting-out" effect) and produce a linear drop in the phase separation temperature as a function of salt concentration. Such anions are effectively repelled from the polymer surface, and the LCST depression mainly stems from their "water withdrawing power," meaning that they can compete with the polymer for hydration water. ${ }^{25,26}$ 
(ii) Weakly hydrated and highly polarizable anions, e.g., thiocyanate $\left(\mathrm{SCN}^{-}\right)$, promote polymer stability in solution (a "salting-in" effect) and raise the phase separation temperature in a nonlinear manner. The stabilization effect originates from preferential partitioning and accumulation of anions at the polymer surface because of the loose bulk hydration and favored interactions with the polymer surface. ${ }^{27,28,29}$ The anion-polymer association can be of different natures, e.g., dispersion forces resulting from the high polarizability of the anions or columbic interactions with partially positive sites on the polymer backbone. ${ }^{30,31,32}$ For many polymers, including PNIPAM, this salting-in effect is limited to relatively low salt concentrations, after which a linear salting-out effect is observed..$^{20,33}$

In the present study, we target two important obscurities in the Hofmeister effect for weakly hydrated anions. First, the accumulation of anions to promote polymer stability is not yet fully understood, although an abundance of studies have been performed to determine why such anions have an affinity for the polymer surface. Previous studies suggested an electrostatic stabilization mechanism; ${ }^{34,35,36}$ nevertheless, further experimental proof is still needed. Our objective is to ascertain the association of weakly hydrated anions with PNIPAM by studying the structural properties of PNIPAM in saline solutions. Second, we investigate the behavior of a PNIPAM solution in a system where a salting-out effect is observed by a weakly hydrated anion to better understand the turning point (i.e., the salting-in to salting-out transition), which is another enigmatic aspect of the Hofmeister effect of weakly hydrated anions.

The Hofmeister effect of three sodium salts on the PNIPAM stability, in bulk and at an interface, is investigated. Sodium fluoride $(\mathrm{NaF})$ and sodium thiocyanate $(\mathrm{NaSCN})$ are selected because these salts have strong salting-out and salting-in effects, respectively. Sodium trichloroacetate (NaTCA) is chosen as the third salt. Trichloroacetate ( $\mathrm{TCA}^{-}$) is a weakly hydrated bulky anion with a significant binding tendency toward proteins and hydrophobic entities. ${ }^{37,38,39}$ The effect of the salts on the PNIPAM stability is inspected using four different 
techniques. Differential scanning calorimetry is performed to obtain the phase separation temperature of the solutions and the enthalpy and entropy of dehydration. Dynamic light scattering is employed to determine the effect of the salts on the hydrodynamic coil size of PNIPAM and aggregation temperature. A quartz crystal microbalance with dissipation is used to monitor the conformational changes of the PNIPAM film in the presence of the salts. Finally, atomic force microscopy colloidal probe measurements are conducted to scrutinize the interactions between the PNIPAM films in the salt solutions at various temperatures.

\section{EXPERIMENTAL SECTION}

\subsection{Materials}

PNIPAM (number average molecular weight $\left(\mathrm{M}_{\mathrm{n}}\right)$ of $475000 \mathrm{~g} / \mathrm{mol}$ and polydispersity index $\left(\mathrm{PDI}=\mathrm{M}_{\mathrm{w}} / \mathrm{M}_{\mathrm{n}}\right)$ of 1.3) and mono thiol-terminated poly $(N$-isopropylacrylamide) (PNIPAM$\mathrm{SH}, \mathrm{M}_{\mathrm{n}}=8000 \mathrm{~g} / \mathrm{mol}, \mathrm{PDI}=1.3$ ) were purchased from Polymer Source Inc. (Dorval, Canada) and used as received. $\mathrm{NaF}(\geq 99 \%), \mathrm{NaTCA}(\geq 97 \%), \mathrm{NaSCN}(\geq 98.5 \%)$, and gold-coated silicon wafer (99.999\% Au, layer thickness of $1000 \AA$ ) were supplied by Sigma-Aldrich. Goldcoated barium titanate glass microspheres (coating thickness: around $20 \mathrm{~nm}$ ) were purchased from Cospheric LLC (Santa Barbara, USA). Degassed ultra-pure Milli-Q water with a resistivity of $18.2 \mathrm{M} \Omega \cdot \mathrm{cm}$ and organic content below $5 \mathrm{ppb}$ was used. All PNIPAM solutions were prepared using a nutating mixer at $5{ }^{\circ} \mathrm{C}$ for $24 \mathrm{~h}$.

\subsection{Methods}

Differential scanning calorimetry (DSC). To analyze the phase separation thermodynamics of the solutions, DSC (Nano DSC, TA Instruments, New Castle, USA) was employed. Measurements were carried out using $0.1 \mathrm{wt} \%$ solutions of PNIPAM in pure water and in 200 $\mathrm{mM}$ salt solutions. The solutions were thermally stabilized at $10{ }^{\circ} \mathrm{C}$ for $30 \mathrm{~min}$ and then heated from 10 to $50{ }^{\circ} \mathrm{C}$ at a heating rate of $0.2^{\circ} \mathrm{C} / \mathrm{min}$. To avoid bubble formation, the measurements were conducted under a constant pressure of 3 bar. The endothermic peak maximum was 
considered to be the phase separation temperature $\left(\mathrm{T}_{\mathrm{ps}}\right)$. The raw heat data were normalized to the monomer molecular weight and concentration to obtain the molar heat capacities. The molar enthalpy of the phase separation $(\Delta \mathrm{H})$ was determined by integrating the area under the peak, and the molar entropy of the phase separation $(\Delta \mathrm{S})$ was calculated according to $\Delta \mathrm{S}=\Delta \mathrm{H}$ $/ \mathrm{T}_{\mathrm{ps}}$. Three measurements were conducted for each solution. (Analysis of the raw heat data is provided in the Supplementary information, Section S1.)

Dynamic light scattering (DLS). The apparent hydrodynamic diameter of PNIPAM in the salt-free and $200 \mathrm{mM}$ saline solutions at various temperatures between 20 and $40{ }^{\circ} \mathrm{C}$ was determined using a DLS apparatus (Zetasizer Nano-ZS, Malvern Instruments, Worcestershire, UK). In brief, this technique measures time-dependent fluctuations in the scattered light intensity resulting from Brownian motion of the polymer coils. By fitting the time correlation function to the measured intensity fluctuations, the diffusion coefficients of the polymer chains are found. The diffusion coefficient is inversely related to the coil size and can be converted into the hydrodynamic diameter using the Stokes-Einstein equation. ${ }^{40}$ Measurements were performed using $0.1 \mathrm{wt} \%$ dilute solutions of PNIPAM in pure water and $200 \mathrm{mM}$ saline solutions. The PNIPAM concentration was optimized to minimize the overlap between the polymer coils in solution (well below the overlap concentration, which was estimated to be around $0.9 \mathrm{wt} \%$ ), while a satisfactory scattering intensity was measured. Before starting the measurements, the solutions were thermally stabilized for $30 \mathrm{~min}$ at $20^{\circ} \mathrm{C}$. For each solution, the measurements were repeated once, and each experimental run consists of $3 \times 12$ consecutive measurements. The standard analysis software of the instrument (Zetasizer software) was used for data analysis and obtaining the size distribution from the fitted autocorrelation function. The Z-average hydrodynamic diameter obtained from cumulants fit was used here. 
Quartz crystal microbalance with dissipation (QCM-D). The conformational change of the PNIPAM film in the salt solutions was monitored using QCM-D (Q-Sense E1, Biolin Scientific, Gothenburg, Sweden). A gold-coated sensor chip (fundamental frequency of 4.95 $\mathrm{MHz}$ ) was repeatedly rinsed in acetone, washed with copious Milli-Q water, and ultimately plasma-cleaned (PDC-32G plasma cleaner, Harrick Plasma) for $5 \mathrm{~min}$ in air under a constant pressure of 500 mTorr. The sensor was immediately placed in the flow module of the apparatus, and the measurement was started at $20{ }^{\circ} \mathrm{C}$ under a $100 \mu \mathrm{L} / \mathrm{min}$ steady flow of degassed MilliQ water. After obtaining a stable baseline for all the harmonics ( $1^{\text {st }}$ to $11^{\text {th }}$ overtones), the bulk shifts of the frequency and dissipation values were measured for each salt solution at various temperatures. In brief, at each constant temperature, the buffer was changed from water to a $200 \mathrm{mM}$ saline solution and then switched back to water. After obtaining the bulk shifts, a 0.1 $\mathrm{wt} \%$ solution of PNIPAM was flowed over the bare sensor for $24 \mathrm{~h}$ at $20^{\circ} \mathrm{C}$ to obtain a polymer layer formed by physically adsorbed PNIPAM chains on the gold surface. The cell was then rinsed with Milli-Q water to remove any loosely adsorbed polymer chains until a stable baseline for all the overtones was reached. The same experimental procedure as used for measuring the bulk shifts was applied on the polymer-coated sensor to study the effect of changing the solvent from water to the saline solutions at various temperatures. To obtain the polymer response, the measured bulk shifts were subtracted from the data. Herein, the third overtone data are used for the analysis and discussion. All measurements on the bare sensor and the polymer-coated sensor were repeated three times and showed very good reproducibility. It should be noted that the same experiments were performed on the thiolterminated PNIPAM; nevertheless, the shifts in frequency and dissipation after bulk subtraction were not large enough to provide reliable trends. Accordingly, only the results of the high molecular weight PNIPAM sample are provided and discussed here. (QCM-D data of the low molecular weight sample are available in the Supplementary information, Section S2.1) 
Atomic force microscopy (AFM). To inspect the interactions between the PNIPAM layers in different salt solutions and at different temperatures, AFM colloidal probe measurements (NanoWizard 3, JPK Instruments AG, Berlin, Germany) were carried out. A tipless rectangular cantilever (HQ:CSC38/Cr-Au, MikroMasch) with an approximate length of $250 \mu \mathrm{m}$, width of $32.5 \mu \mathrm{m}$, thickness of $1 \mu \mathrm{m}$, and normal spring constant of $0.09 \mathrm{~N} \cdot \mathrm{m}^{-1}$ was used. The accurate normal spring constant of the cantilever (with no particle attached) was obtained using the thermal noise method. ${ }^{41}$ A gold-coated spherical particle (Cospheric LLC, Santa Barbara,USA) with a diameter of $20 \pm 0.1 \mu \mathrm{m}$ (measured using a Nikon Eclipse LV100ND optical microscope and the Infinity Analyze image processing software) was glued to the end of the cantilever using a small amount of a two-component epoxy adhesive (Araldite 2000 Plus). ${ }^{42,43}$ A goldcoated silicon wafer (root mean square roughness below $2.5 \mathrm{~nm}$ over a $1 \mu \mathrm{m} \times 1 \mu \mathrm{m}$ area, obtained from AFM imaging) was used as the flat substrate. To ensure stability of the PNIPAM layers during the measurements, PNIPAM chains were chemically grafted at one end to the gold surface using gold-thiol chemistry. ${ }^{44}$ The cantilever with the attached gold-coated particle and the substrate were plasma-cleaned for $5 \mathrm{~min}$ and then immersed in a $0.1 \mathrm{wt} \%$ solution of thiol-terminated PNIPAM for $2 \mathrm{~h}$. After rinsing with copious water, the samples were immediately used for the measurements. During the force measurements, the temperature of the solution was controlled with an accuracy of $\pm 0.1{ }^{\circ} \mathrm{C}$ using a BioCell (JPK Instruments). Two syringe pumps (Aladdin syringe pump, World Precision Instruments, Sarasota, USA) were used to exchange the solutions in the AFM BioCell. When exchanging the solution or changing the cell temperature, the system was subjected to $15 \mathrm{~min}$ of stabilization time. For each measurement condition, 25 force curves were collected at various surface positions, which were equally separated over an area of $5 \mu \mathrm{m} \times 5 \mu \mathrm{m}$. The force measurements were conducted with an approach and retraction velocity of $300 \mathrm{~nm} / \mathrm{s}$, where the contribution from hydrodynamic forces could be neglected. ${ }^{45}$ The standard software of the instrument (JPKSPM 
Data Processing) was used to process the raw data and analyze the force curves, as described in detail elsewhere. ${ }^{46}$

\section{RESULTS AND DISCUSSION}

Before discussing our findings, a general prelude on some aspects of PNIPAM hydration and phase transition is useful. ${ }^{11,47,48}$ Below the phase separation temperature, PNIPAM chains adopt a swollen random coil conformation and are highly hydrated, with a water content of around $90 \% .{ }^{49,50}$ Regarding the structure of water molecules surrounding the PNIPAM chains, two types of hydration structures were previously suggested. (i) Water molecules that are hydrogen-bonded to the amide groups and (ii) water molecules neighboring the hydrophobic backbone and isopropyl side groups, generally referred to as "hydrophobic hydration." Upon heating the solution to the phase separation temperature, the PNIPAM coils abruptly shrink and adopt a collapsed conformation, while tending to aggregate because of attractive interchain interactions. The hydrogen-bonded water molecules are almost unaffected by the phase transition, and a collapsed PNIPAM coil still contains nearly $60 \%$ water. $^{10,51,52}$ Accordingly, it is the hydrophobic effect that dominantly governs the phase separation of PNIPAM. ${ }^{10,11}$ Compared to the bulk structure, water molecules in the hydrophobic hydration shell form stronger hydrogen bonds (favorable enthalpic term), but possess a lesser degree of freedom (unfavorable entropic term). The balance of these two contrary factors determines the stability of PNIPAM in water at different temperatures. Below the phase separation temperature, the favorable enthalpic term keeps PNIPAM in the solution. Upon passing the phase separation temperature, the entropic term prevails and water molecules escape from the hydrophobic hydration cage to acquire a higher entropic state. Knowing the determining role of the hydrophobic effect, the next step is to assess it in the salt solutions.

Ions can influence the hydrophobic effect of water on small nonpolar solutes. ${ }^{53,54,55,56}$ Considering the surface exclusion of strongly hydrated anions, such ions could affect the 
hydrophobic effect by changing the enthalpy and entropy values of hydrogen bond formation in the bulk. As mentioned above with respect to pure water, formation of hydrogen bonds at the hydrophobic surfaces is enthalpically favorable but entropically costly. The combination of these two factors provides a net positive contribution to the free energy. The situation is reversed in strongly hydrated salt solutions, where the ion-water interaction is relatively stronger than the water-water interaction. Accordingly, the formation of hydrogen bonds in the hydrophobic hydration layer in the saline solutions is enthalpically costly but entropically favored. However, the net contribution to the free energy is even more positive than that of pure water, providing a relatively stronger hydrophobic effect in such saline solutions. Regarding the surface affinity of weakly hydrated anions, the hydrophobic effect can be affected in two manners. On the one hand, the anions can modify the hydrophobic effect by changing the energetics of hydrogen bond formation. On the other hand, the accumulation of the anions at the surface constrains the space for water molecules; therefore, the number of water molecules in the hydrophobic shell decreases (surface effect). After becoming acquainted with these principles, henceforth, we discuss our findings on the Hofmeister effect of salts.

3.1 DSC measurements in bulk solution: The DSC data of $0.1 \mathrm{wt} \%$ PNIPAM in pure water and saline solutions are presented in Figure 1 and Table 1. In agreement with former studies, PNIPAM undergoes a sharp endothermic phase separation in aqueous solutions at around 32 ${ }^{\circ} \mathrm{C}$, which is accompanied by an increment in the system entropy. Considering hydrophobic dehydration as the primary driving force for phase separation, the enthalpy and entropy changes thus correspond to the transfer of water molecules from the hydrophobic hydration shell to the bulk solution. 5,10 The adsorbed heat resulting from the phase separation correlates to breakdown of the more strongly hydrogen-bonded water structures that surround the hydrophobic groups (which are often referred to as the "ice-like" structures). On the other hand, 
the observed positive entropy change of the phase separation indicates a higher degree of freedom for the water molecules that are transferred to the bulk solution.

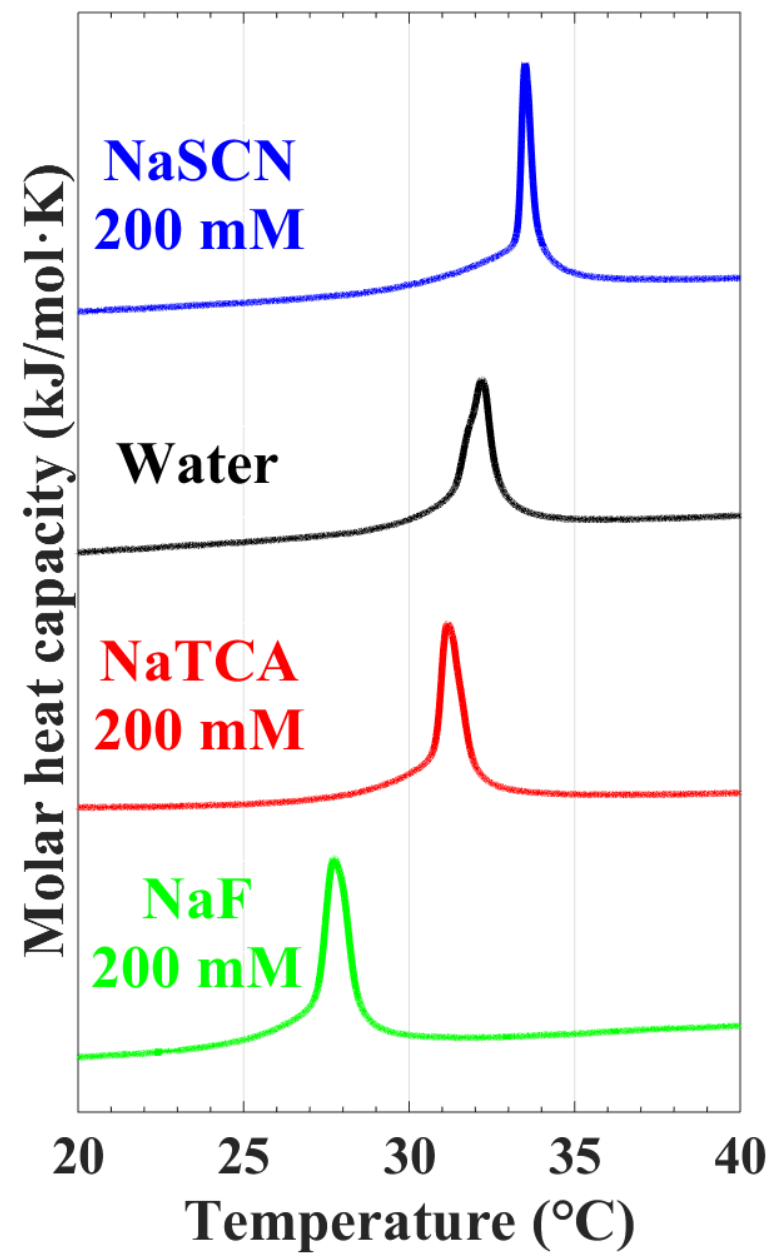

Figure 1 DSC thermograms of $0.1 \mathrm{wt} \%$ PNIPAM solutions

Table 1 DSC data of $0.1 \mathrm{wt} \%$ PNIPAM salt-free and saline solutions; the enthalpy and entropy change per monomer unit are reported.

\begin{tabular}{|c|c|c|c|}
\hline Sample & $\mathbf{T}_{\text {peak }}\left({ }^{\circ} \mathbf{C}\right)$ & $\Delta \mathbf{H}(\mathbf{k J} / \mathbf{m o l})$ & $\Delta \mathbf{S ~ ( J / m o l \cdot K )}$ \\
\hline NaSCN 200 mM & $33.52( \pm 0.06)$ & $3.85( \pm 0.08)$ & $12.60( \pm 0.25)$ \\
\hline Water & $32.27( \pm 0.01)$ & $4.16( \pm 0.10)$ & $13.60( \pm 0.35)$ \\
\hline TCA 200 mM & $31.06( \pm 0.03)$ & $4.11( \pm 0.02)$ & $13.50( \pm 0.10)$ \\
\hline NaF 200 mM & $27.75( \pm 0.01)$ & $4.42( \pm 0.07)$ & $14.70( \pm 0.25)$ \\
\hline
\end{tabular}


With respect to the effects of the salts, $200 \mathrm{mM} \mathrm{NaF}$ lowers the phase separation temperature by $4.5^{\circ} \mathrm{C}$, whereas $200 \mathrm{mM} \mathrm{NaSCN}$ increases the phase separation temperature by $1.25^{\circ} \mathrm{C}$, in accordance with the hydration power of their constituent anions. Despite the poor hydration power of $\mathrm{TCA}^{-}, 200 \mathrm{mM} \mathrm{NaTCA}$ shows a salting-out effect and leads to a decrement of the phase separation temperature by $1.2{ }^{\circ} \mathrm{C}$. Besides the phase separation temperature, the salts also affect the enthalpy and entropy change of dehydration. Compared to the salt-free solution, $200 \mathrm{mM} \mathrm{NaF}$ increases the enthalpy and entropy changes, while the values are relatively smaller in the NaSCN solution. The former observation supports the idea of having a stronger hydrophobic effect in the strongly hydrated salt solutions. On the other hand, the latter result implies that accumulation of the weakly hydrated anions at the polymer surface can interfere with hydrophobic hydration. Unlike the two other salts, $200 \mathrm{mM} \mathrm{NaTCA}$ has a negligible effect (i.e., within the range of the experimental uncertainties) on the phase separation energetics.

Regarding the strong affinity of $\mathrm{TCA}^{-}$to accumulate at hydrophobic and polymer surfaces, attenuation of the hydrophobic hydration and then a decrement in the enthalpy and entropy values is anticipated, which is an effect similar to that in the $\mathrm{NaSCN}$ solution. This may suggest an intensifying effect on the hydrophobic hydration to counterbalance the surface-related effect so that the enthalpy and entropy values remain almost the same. Thus, we will further investigate the idea of the strong association between $\mathrm{TCA}^{-}$and PNIPAM in the following sections. 


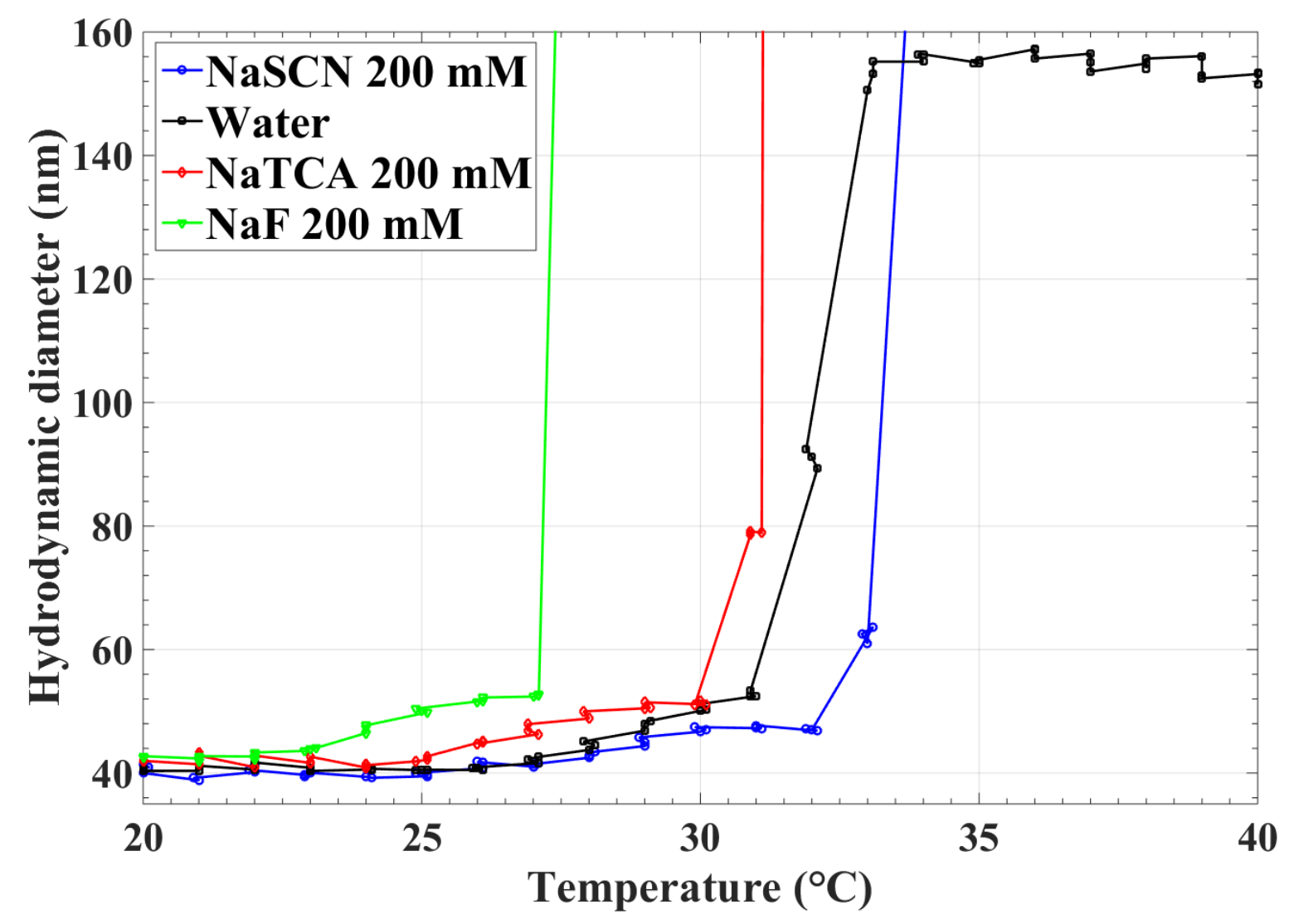

Figure 2 Hydrodynamic diameter (Z-average) of PNIPAM as a function of temperature in the saline and salt-free solutions

3.2 DLS measurements in bulk solution: Figure 2 illustrates the effect of temperature and salts on the apparent hydrodynamic diameter of PNIPAM in solution. At temperatures well below the phase separation point, PNIPAM has a hydrodynamic diameter of $\sim 41 \mathrm{~nm}$, which is in agreement with the previously suggested scaling law between the hydrodynamic diameter and the molecular weight of PNIPAM ${ }^{57}$ Within the experimental uncertainties, the salts generally appear to have an insignificant effect on the hydrodynamic coil size. Additionally, all of the samples show a considerable increment in the apparent hydrodynamic diameter near their phase separation temperatures. We suggest that this is not a real change in the coil size, but is probably a result of stronger inter-chain interactions, and thus slower diffusion, when approaching the phase separation temperature. This speculation is further supported by additional DLS measurements conducted on solutions with lower and higher concentration of 
PNIPAM. (See the supplementary information, Section S3) For the salt-free and all the saline solutions, there is a good correlation between the temperatures at which the apparent hydrodynamic size (from DLS) and the heat capacity (from DSC) begin to increase (compare Fig. 1 and 2).

Another interesting finding is the formation of nano-sized PNIPAM mesoglobules after the phase separation temperature in water, whereas macroscopic segregation of the polymer-rich and water-rich phases occurs in all of the saline solutions. Although this topic is beyond the scope of our paper, it is worth a brief discussion. As reported, PNIPAM chains of specific molecular weights and at certain concentrations may form meso-stable, nano-sized globular aggregates after the collapse temperature. ${ }^{11,58}$ There is still a disagreement about the stabilization mechanisms, but two explanations have gained more acceptance. ${ }^{59,60}$ First, PNIPAM chains form aggregates to minimize their hydrophobic surface area, but the hydrated hydrophilic parts can stabilize the globules and hamper macroscopic flocculation. Second, the globules are partially charged, either because of the presence of an ionic initiator in the PNIPAM chain or ion adsorption from solution, and are thus electrostatically repelled from each other. To investigate if the PNIPAM mesoglobules in the salt-free solution are charged, zeta potential measurements were conducted as a function of temperature, in which an average zeta potential of around $-12 \mathrm{mV}$ was obtained for the mesoglobules. (See the supplementary information, Section S3) Accordingly, the observed cessation of mesoglobule formation in all of the saline solutions suggests that the electrostatic stabilization mechanism plays an important role in mesoglobule stability, even though the other mechanism can still contribute. 


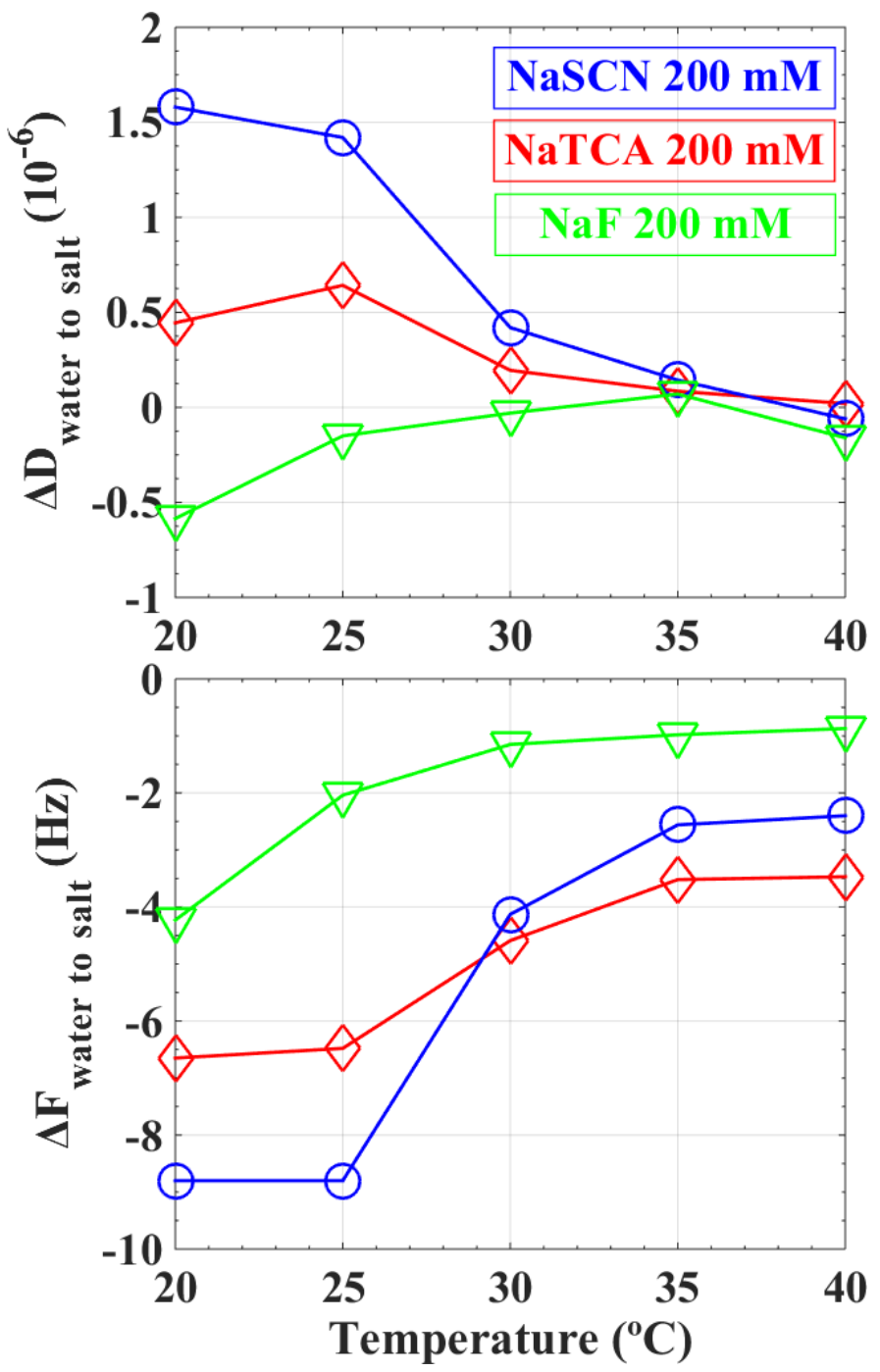

Figure 3 Subtracted dissipation $\left(\Delta \mathrm{D}_{\text {water to salt }}\right)$ and frequency shifts $\left(\Delta \mathrm{F}_{\text {water to salt }}\right)$ for changing the solvent from water to the saline solutions at various temperatures.

\subsection{QCM-D study of a physically adsorbed PNIPAM film on the gold surface: Figure 3}

depicts the dissipation and frequency shifts resulting from changing the solvent from water to the saline solutions at various temperatures. (The comprehensive analysis of PNIPAM physical adsorption on the gold surface and the testing durability of the prepared film are available in the Supplementary information, Section S2.2) During a QCM-D measurement, the drive generator output repeatedly ceases and the subsequent decay of the sensor oscillation is monitored. Accordingly, the dissipation (damping) factor (D) is determined as the energy dissipated per oscillation divided by the total energy stored in the system. A soft film attached 
to the sensor is deformed during oscillation and hence can provide a high dissipation value. In contrast, a rigid polymer layer follows the oscillation with no significant deformation and thus has a small damping factor. Accordingly, the dissipation value can provide semi-quantitative structural and conformational information about the swelling and collapse of the polymer film.

The oscillation frequency $(\mathrm{F})$ is sensitive to the total mass coupled with the sensor, which in the present case includes the physically adsorbed PNIPAM chains, the associated water molecules (hydrodynamic water content) and the adsorbed and trapped ions. Considering the polymer chains to remain intact on the surface with no desorption, the subtracted frequency shift corresponds to variation in the solvent content of the PNIPAM layer, as well as adsorption of the ions. With respect to the former, dehydration of PNIPAM chains gives rise to a positive frequency shift, and vice versa. Regarding the latter, adsorption of ions to the polymer surface or the bare gold surface can give rise to a negative frequency shift. In addition to the anionpolymer association, one can expect adsorption of sodium cations to the bare gold surface, regarding the partial negative charge present on the gold surface. ${ }^{61,62}$

First, we investigate how changing the solvent from water to a saline solution can alter the dissipation factor of the PNIPAM film at various temperatures. By doing so, a change in the dissipation factor value ( $\left.\Delta \mathrm{D}_{\text {water to salt }}\right)$ is detected, which can be either positive (the film becomes softer and more dissipative) or negative (the film becomes more rigid and less dissipative). As a general observation in Figure 3, the PNIPAM film is more responsive to the addition of salts at low temperatures than at high temperatures. The salts provide almost no change in the dissipation factor $(\Delta \mathrm{D} \approx 0)$ at 35 and $40{ }^{\circ} \mathrm{C}$, indicating a fully collapsed state at these temperatures. In accordance with the DSC and DLS results, the collapse of the PNIPAM film commences at temperatures around $30{ }^{\circ} \mathrm{C}$ because the polymer film response to a change in the temperature or addition of the salts is notably weaker than that observed at 20 and $25^{\circ} \mathrm{C}$. This can also be seen from the subtracted dissipation shifts resulting from heating the PNIPAM 
film in the salt-free solution. (See the Supplementary information, Section S2.2) It should be considered that polymers confined at the solid-liquid interface typically have a lower collapse temperature than that in bulk solution because of the entropic restriction imposed by the conformational confinement. ${ }^{63,64,65}$ Regarding the effect of the salts at 20 and $25{ }^{\circ} \mathrm{C}$, the observed trend of the Hofmeister series $(\mathrm{NaSCN}>\mathrm{NaTCA}>\mathrm{NaF})$ is similar to that of the DSC and DLS results, though with an important distinction. Changing the solvent from water to the NaF solution is accompanied by a negative $\Delta \mathrm{D}$, meaning that the PNIPAM film becomes relatively rigid and partially collapses. In contrast, changing the solvent from water to either the NaTCA or NaSCN solutions provide a positive $\Delta \mathrm{D}$ value, which suggests swelling of the PNIPAM film from surface partitioning of the anions. Therefore, although $200 \mathrm{mM}$ NaTCA produces a salting-out effect on the phase separation temperature of PNIPAM (inferred from the DSC and DLS measurements), our QCM-D findings imply the surface affinity of TCA ${ }^{-}$and a swelling of the polymer film. However, the $\Delta \mathrm{D}$ values are relatively smaller for NaTCA than $\mathrm{NaSCN}$ at all temperatures, and we suggest that this is another indication of an alternative destabilizing effect in the NaTCA solution.

The situation is more complicated in case of the frequency shifts $\left(\Delta \mathrm{F}_{\text {water to salt }}\right)$. According to Figure 3, changing the solvent from water to each of the saline solutions is associated with a negative frequency shift; however, the effect is evidently larger for the NaTCA and NaSCN solutions than the NaF solution. Moreover, it can be seen that the frequency shifts become considerably smaller by increasing the temperature, and a plateau is found for each saline solution at 35 and $40{ }^{\circ} \mathrm{C}$, where the PNIPAM layer is in fully collapsed state. The observations can be discussed in terms of swelling/collapse of the PNIPAM layer, as well as density of the solution within the layer.

With respect to the NaF solution, the dissipation data indicated partial conformational collapse of the PNIPAM layer; however, the salt solution within the layer has a relatively larger 
density than pure water, thus can give rise to a negative frequency shift. At 35 and $40{ }^{\circ} \mathrm{C}$ where the PNIPAM layer is fully collapsed, a smaller amount of the solvent is coupled with the layer, which can explain the relatively smaller frequency shifts. The notably larger frequency shifts found for the NaTCA and NaSCN solutions can be reasoned in the same manner. The dissipation data revealed that the PNIPAM film swells in both the solutions, meaning that more solvent is coupled with the oscillating sensor. The solution densities are also larger than pure water, which can contribute to a negative frequency shift. Furthermore, the preferential accumulation of the weakly hydrated anions within the PNIPAM layer can produce a negative frequency shift. The latter effect can be more clearly identified at high temperatures, i.e., 35 and $40{ }^{\circ} \mathrm{C}$, where the PNIPAM layer is fully collapsed in all the salt solution; but the frequency shifts are considerably larger in the NaTCA and NaSCN solutions.

3.4 Surface forces between PNIPAM layers: The force curves measured between the grafted PNIPAM layers at 20 and $40{ }^{\circ} \mathrm{C}$ in the various salt solutions are provided in Figure 4 and Table 2. Before discussing the results in more detail, a brief recapitulation of the possible interactions between two polymer-coated surfaces in the aqueous solution would be appropriate. ${ }^{66}$ When the surfaces are approaching each other, the dangling chains from one surface can begin to interact with the chains from the other surface and with the bare opposite surface (if the surfaces are not fully covered by the polymers). Depending on the surface affinity of the polymer, the surface coverage, and the solvent quality, these interactions will manifest themselves as either attractive bridging forces or steric repulsions. ${ }^{67,} 68,69,70,71,72,73$ Based on the QCM-D measurements, we know that PNIPAM has a strong affinity for the gold surface at all the investigated temperatures; hence, attractive chain-substrate bridging is likely in our system. With respect to PNIPAM chain-chain interactions, we postulate steric repulsive forces at $20^{\circ} \mathrm{C}$, where PNIPAM is fully soluble in water, and attractive inter-chain interactions at $40{ }^{\circ} \mathrm{C}$, where PNIPAM is partly dehydrated and insoluble in water. 

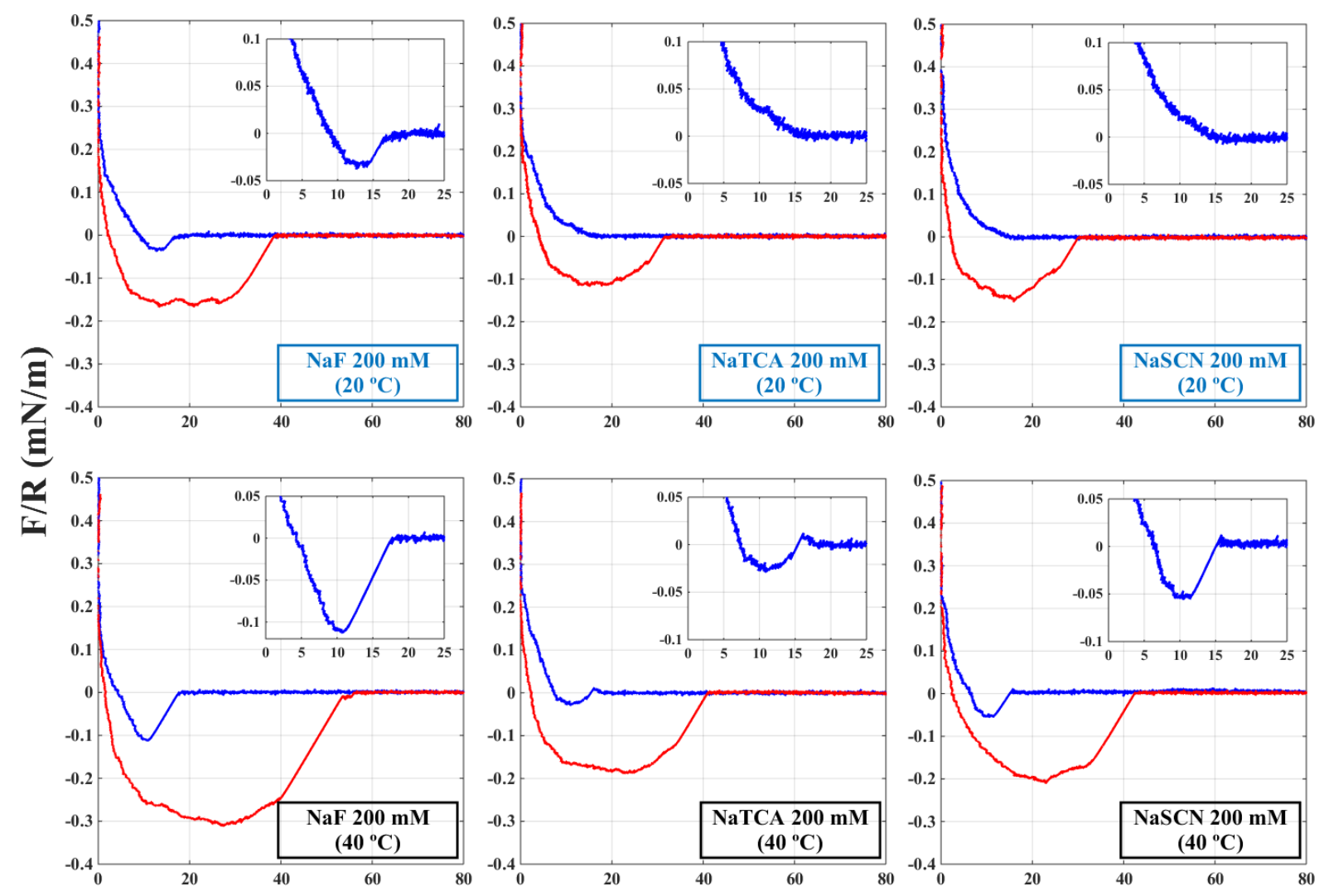

Separation distance $(\mathrm{nm})$

Figure 4 Approach (blue line) and retract (red dotted line) force-distance curves between two PNIPAM layers in the salt solutions at $20^{\circ} \mathrm{C}$ (top row, hydrated state) and $40{ }^{\circ} \mathrm{C}$ (bottom row, collapsed state); insets show the contact point in the approach step.

Table 2 Statistical data of the AFM measurements

\begin{tabular}{|c|c|c|}
\hline Solution & $\begin{array}{c}\text { Adhesion Energy } \\
\mathbf{2 0}^{\circ} \mathbf{C}\left(\mathbf{1 0}^{-17} \mathbf{J}\right)\end{array}$ & $\begin{array}{c}\text { Adhesion Energy } \\
\mathbf{4 0}^{\circ} \mathbf{C}\left(\mathbf{1 0}^{-\mathbf{- 1 7}} \mathbf{J}\right)\end{array}$ \\
\hline NaSCN $200 \mathrm{mM}$ & $2.55( \pm 0.55)$ & $6.70( \pm 0.60)$ \\
\hline TCA $200 \mathrm{mM}$ & $2.40( \pm 0.41)$ & $6.10( \pm 0.81)$ \\
\hline $\mathrm{NaF} 200 \mathrm{mM}$ & $4.55( \pm 0.82)$ & $12.45( \pm 1.50)$ \\
\hline
\end{tabular}

After contact has been reached, a soft repulsive region corresponding to the compression of the polymer layers is predicted, regardless of whether the initial interactions were attractive or repulsive. The determining factor here is the solvent quality, which controls the polymer chain 
conformation. The more the polymer chains are swollen and stretched in the solution (good solvent condition), the more long-range this repulsive force will be. The repulsive double layer forces - resulting from the ions adsorbed to the gold substrate or the polymers — can be present; nonetheless, such forces are extremely short-ranged because of the small Debye length $(0.68$ $\mathrm{nm}$ ) in the $200 \mathrm{mM}$ saline solutions. Moreover, the repulsive hydration force of the sodium cations at the gold surface is likely; however, it tends to be more short-ranged $(\sim 1-2 \mathrm{~nm})$ than repulsive compression of the polymer layers. ${ }^{74}$ Ultimately, we do not expect van der Waals forces between the gold surfaces to be of significant magnitude, considering the roughness of the gold surfaces and the presence of a polymer layer. ${ }^{75}$ With this in mind, we discuss the obtained force-distance profiles in each salt solution.

The approach force curve for $200 \mathrm{mM} \mathrm{NaF}$ at $20{ }^{\circ} \mathrm{C}$ exhibits an attractive jump-in, after which a repulsive force starts at surface separation of around $13 \mathrm{~nm}$. This repulsion can be ascribed to the compression of the polymer layers. The retraction force curve also demonstrates a relatively strong adhesion between the two surfaces. Because PNIPAM is fully soluble in water at this temperature, the strong attractive forces observed in the approach and retrace curves are chiefly correlated to the PNIPAM-gold bridging forces. As mentioned above, the amount of the adsorbed polymer on the surface determines if the sum of bridging and steric forces is attractive or repulsive. Accordingly, a purely repulsive force profile is obtained at high surface coverage, whereas at low surface coverage only attractive bridging force will exist. Herein, a rough estimation based on the QCM-D data can be made to assess the amount of PNIPAM grafted to the gold surface. According to the adsorption curve and by using the Sauerbrey equation (See the Supplementary information, Section S2.1), the adsorbed hydrodynamic mass is estimated to be nearly $370 \mathrm{ng} / \mathrm{Cm}^{2}$. As previously reported ${ }^{76}$, the water content of a PNIPAM film obtained by grafting-to method is approximately $70 \%$. Accordingly, the grafting density of PNIPAM chains on the gold surface is estimated to be around 0.1 
chain $/ \mathrm{nm}^{2}$, which together with the estimated radius of gyration of the PNIPAM chain ${ }^{77}$, suggest a relatively low grafting density, thus can explain the observed purely attractive bridging force. By increasing the solution temperature to $40^{\circ} \mathrm{C}$, the jump-in becomes even more pronounced, while the adhesion energy is almost tripled. Such an increment is mainly due to the presence of PNIPAM-PNIPAM inter-chain interactions at the collapsed state, which can be caused by either hydrophobic interactions or hydrogen bonding between the chains. Accordingly, both PNIPAM-gold and PNIPAM-PNIPAM bridging forces can contribute to the attractive jump-in and adhesion between the surfaces. One can also argue that the PNIPAM chains in bad solvent condition (above the phase separation temperature) are less swollen than in good solvent condition (below the phase separation temperature) thus chain-surface bridging is more likely. The onset of repulsive compression region is decreased to around $10 \mathrm{~nm}$, which can be attributed to partial collapse and shrinkage of the polymer layer upon heating.

The force-distance curves in the $200 \mathrm{mM} \mathrm{NaSCN}$ differ greatly from those in the $200 \mathrm{mM}$ $\mathrm{NaF}$ solution. At $20^{\circ} \mathrm{C}$, a purely repulsive force profile with no attractive jump-in is found at the separation distance of around $15 \mathrm{~nm}$, and the adhesion energy is significantly smaller than in the NaF solution. Therefore, the PNIPAM-gold bridging forces are evidently weaker in the NaSCN solution, which can be explained in two ways. On the one hand, the QCM-D data indicated that $200 \mathrm{mM}$ NaSCN promotes swelling of PNIPAM, which can hamper chainsubstrate bridging. One the other hand, one can argue that accumulation of the anions within the layers can attenuate the attractive interactions through either electrostatic repulsive forces or weakening of the hydrophobic interactions. Heating the solution to $40{ }^{\circ} \mathrm{C}$ significantly changes the force-distance profile. An attractive jump-in is detected along with a notable gain in the adhesion energy. This again indicates the presence of PNIPAM-gold and PNIPAMPNIPAM interactions. Nevertheless, the obtained adhesion energies are almost 50\% smaller than that in the NaF solution, meaning that the chain-surface and chain-chain interactions are 
considerably weaker in the NaSCN solution. This observation affirms that even the collapsed PNIPAM layer is associated with the weakly hydrated $\mathrm{SCN}^{-}$anions, in accordance with the QCM-D findings. Moreover, the separation distance at which the repulsive force kicks in is decreased to around $10 \mathrm{~nm}$ upon heating, indicating vertical collapse of the PNIPAM layer.

The force profiles in $200 \mathrm{mM} \mathrm{NaTCA}$ appear quite similar to those in the NaSCN solution. The attractive jump-in is not observed At $20{ }^{\circ} \mathrm{C}$; moreover, the adhesion energy and repulsion distance values are quite comparable to those in the NaSCN solution. The force curves at 40 ${ }^{\circ} \mathrm{C}$ also represent the similarity in the interactions. Thus, despite the observed salting-out effect by $200 \mathrm{mM}$ NaTCA, the AFM measurements ascertain accumulation of $\mathrm{TCA}^{-}$within the PNIPAM layer, weak attractive PNIPAM-gold and PNIPAM-PNIPAM interactions, and PNIPAM film swelling in such a solution. Another intriguing observation in the NaTCA and $\mathrm{NaSCN}$ solutions at $40{ }^{\circ} \mathrm{C}$ is a weak repulsion force before the jump-in. While Figure 4 only illustrates a single representative force curve for each case, this is a notable observation. We observed this repulsive force in nearly all of the 25 force-distance measurements in NaTCA and almost half of the measurements in NaSCN (see the Supplementary information, Figure S13). Such a repulsive force can be considered as further evidence for surface partitioning of the weakly hydrated anions within the PNIPAM film and possible electrostatic repulsions between the PNIPAM films that result from the adsorbed anions. This repulsion could also occur at temperatures below the phase separation temperature, i.e., $20{ }^{\circ} \mathrm{C}$, but not plainly distinguishable from the purely repulsive approach force curve.

Concisely, the observations from the AFM measurements affirm surface partitioning of the two weakly hydrated anions, both below and above the phase separation temperature. The relatively weak PNIPAM-gold and PNIPAM-PNIPAM interactions together with the observed repulsive force at $40{ }^{\circ} \mathrm{C}$ apparently stem from the inter- and intra-chain electrostatic repulsions within the polymer film. The appreciably stronger attractive bridging forces in the NaF solution 
can be reasoned in two ways. On the one hand, the attractive forces between the two hydrophobic surfaces are relatively larger in strongly hydrated salt solutions. On the other hand, the chance of polymer-substrate bridging will be larger for a less swollen PNIPAM film.

3.5 Further discussion of results: The first objective of this study was to ascertain the surface partitioning of the weakly hydrated anions and thereupon scrutinize the following effects on the properties of PNIPAM in solution. This was chiefly addressed by our AFM and QCM-D results, which demonstrated that the conformation and interaction of PNIPAM in the two weakly hydrated salt solutions are utterly distinguishable from those in the NaF solution. Accordingly, either of the poorly hydrated anions could adsorb to the PNIPAM surface and produce a stabilization effect, regardless of whether the overall Hofmeister effect is a saltingin or salting-out effect. With respect to the stabilization mechanism, the observed swelling of the PNIPAM film could indicate the presence of inter- and intra-chain electrostatic repulsions within the polymer film. The relatively weak attractive PNIPAM-gold and PNIPAM-PNIPAM interactions further support this claim; nonetheless, it could also indicate the solvent-mediated attenuation of the hydrophobic interactions in such salt solutions. The weak repulsive force before the jump-in, observed at $40{ }^{\circ} \mathrm{C}$ in the NaSCN and NaTCA solutions, also strengthens the electrostatic stabilization hypothesis. To picture it more simply, the polymer film is in a hydrophobically collapsed state, but the weakly hydrated anions can be found within it, which could then produce electrostatic repulsions and some degree of swelling.

The second objective of the study was to address the salting-out effect by a weakly hydrated salt, i.e., a $200 \mathrm{mM}$ NaTCA solution. In this instance, $\mathrm{TCA}^{-}$is strongly adsorbed to the PNIPAM surface and has a stabilizing facet, even though it has an overall salting-out effect. Now the following question arises: what is the origin of the salting-out effect? Several arguments can be advanced to rationalize it. First, the poorly hydrated anions cannot be further accommodated at the polymer surface above a certain salt concentration; in other words, the 
polymer-water interface becomes saturated. Henceforth, the anions in the bulk solution might compete with the polymer for the hydration water and thus produce a salting-out effect. ${ }^{20,21}$ Although the idea of surface saturation seems rational, we strongly doubt that the observed difference between the phase separation temperatures in the $200 \mathrm{mM} \mathrm{NaSCN}$ and $200 \mathrm{mM}$ NaTCA solutions is solely caused by this effect. Both the anions are poorly hydrated; therefore, there should not be a significant difference in their abilities to withdraw water molecules from the polymer. Second, $\mathrm{TCA}^{-}$may have a relatively strong salting-out effect at the PNIPAM hydrophobic surface. ${ }^{19,25}$ This idea was partly discussed in the DSC results section, where we reasoned that the accumulation of $\mathrm{TCA}^{-}$at the PNIPAM surface should reduce the phase separation enthalpy and entropy values (surface effect), whereas the change in water hydrogen bonding energetics may have a salting-out effect. Therefore, this might be the reason that the total enthalpy and entropy change values are almost the same as that in pure water. Such a destabilization mechanism has been formerly suggested in terms of the change in surface tension at the polymer/water interface. ${ }^{13,19,25}$

Finally, it has recently been discussed in some MD simulation studies that strongly attractive cosolutes, e.g., perchlorate and urea, could induce a compact and collapsed polymer network through collective binding and a following weak cross-linking effect. ${ }^{78,79,80}$ As argued by the authors of those studies, such a partially collapsed state would have quite a different structure and different properties from those of the collapsed state found for purely repulsive cosolutes (strongly hydrated ions) because the polymer coils are highly saturated by the attractive cosolutes. Regarding the weak hydration and considerably strong binding affinity of $\mathrm{TCA}^{-}$to macromolecules, such a cross-linking-like effect could be the main source of the observed salting-out effect. The PNIPAM film showed identical properties in both the NaSCN and NaTCA solutions, all suggesting the accumulation of anions within the film and a subsequent stabilization effect. However, a notable difference in their corresponding phase separation 
temperatures was detected. Such a huge difference in the specific ion effect most likely originated from the suggested cross-linking effect, rather than the surface tension and saturation effects. Our argument regarding the accumulation of TCA ${ }^{-}$in the PNIPAM film is in agreement with this view. Adopting this picture, we could also explain the relatively smaller dissipation values (relatively more rigid conformation) for the PNIPAM film in the NaTCA solution compared to that in the NaSCN solution, which was partially discussed in the QCM-D results section. Considering the PNIPAM chains are partially involved with each other through physically crosslinked sites, a relatively more rigid and less dissipative structure is expected, even though the layer is swollen.

\section{SUMMARY AND CONCLUSION}

In the present work, we investigated the Hofmeister effect of three sodium salts on PNIPAM, both in bulk aqueous solution and at the gold-water interface. Addition of $200 \mathrm{mM} \mathrm{NaF}$ (strongly hydrated anion) demonstrated all the generic features of a merely destabilizing salt. For PNIPAM in the bulk phase, the addition of NaF led to a large decline in the phase separation temperature (salting-out effect) and a notable gain in the enthalpy and entropy changes of dehydration. While the former mainly correlates to the surface exclusion and waterwithdrawing power of the anion, the latter is suggested to represent a stronger hydrophobic effect. QCM-D studies of the physically adsorbed PNIPAM layer on the gold surface confirmed conformational collapse and shrinkage in the NaF solution. AFM force measurements indicated considerably strong PNIPAM-gold and PNIPAM-PNIPAM attractive interactions. Addition of $200 \mathrm{mM} \mathrm{NaSCN}$ (weakly hydrated anion) represented all the characteristics of a stabilizing salt. In the bulk phase, the addition of NaSCN increased the phase separation temperature and reduced the enthalpy and entropy values. The former is attributed to the anion-polymer association, while the latter is most probably due to the spatial 
interference of the anions with water molecules in the hydrophobic hydration shell. QCM-D studies demonstrated swelling of the PNIPAM film in the NaSCN solution, which implies accumulation of the anions within the film. AFM based force-distance measurements revealed relatively weak attractive forces, which further reinforce the idea of having a polymer film saturated with the anions. Finally, studies of the effect of $200 \mathrm{mM} \mathrm{NaTCA}$ (weakly hydrated anion) revealed features of both a stabilizing and a destabilizing salt. In the bulk solution, a decrement in the phase separation temperature was found, whereas the enthalpy and entropy values remained essentially constant. Although the former implies a pure destabilization effect, the latter raised the suspicion of simultaneous salting-out and salting-in effects. This speculation was bolstered by the QCM and AFM measurements, which demonstrated a swollen film conformation in the NaTCA solution and weak chain-substrate and chain-chain interactions, quite similar to the findings in the NaSCN solution. Therefore, the salting-in facet of NaTCA is evidently of the same nature as that in the NaSCN solution, resulting from the interplay between the polymer and anions.

\section{ASSOCIATED CONTENT}

The following files are available free of charge.

Analysis of the DSC data, QCM-D data of the PNIPAM physical adsorption to gold the surface together with the thiol-terminated sample, additional DLS and Zeta potential measurements, AFM force curves, and the tapping mode images are provided. (PDF)

\section{AUTHOR INFORMATION}

To whom correspondence should be addressed. E-mail: esth@kemi.dtu.dk. Telephone: $(+45)$ 45252439.

\section{ACKNOWLEDGEMENTS}


We would like to acknowledge the Swedish Research Council (VR) for financial support, which was transferred to the Technical University of Denmark via the EU initiative "Money Follow Researcher."

\section{REFERENCES}

1. Mendes, P. M. Stimuli-responsive surfaces for bio-applications. Chemical Society Reviews 2008, 37 (11), 2512-2529.

2. Dedinaite, A.; Thormann, E.; Olanya, G.; Claesson, P. M.; Nyström, B.; Kjøniksen, A.L.; Zhu, K. Friction in aqueous media tuned by temperature-responsive polymer layers. Soft Matter 2010, 6 (11), 2489-2498.

3. Bodvik, R.; Thormann, E.; Karlson, L.; Claesson, P. M. Temperature responsive surface layers of modified celluloses. Physical Chemistry Chemical Physics 2011, 13 (10), 4260-4268.

4. Liu, C.; Thormann, E.; Claesson, P. M.; Tyrode, E. Surface grafted chitosan gels. Part II. Gel formation and characterization. Langmuir 2014, 30 (29), 8878-8888.

5. Halperin, A.; Kröger, M.; Winnik, F. M. Poly (N-isopropylacrylamide) Phase Diagrams: Fifty Years of Research. Angewandte Chemie International Edition 2015, 54 (51), 15342-15367.

6. Guan, Y.; Zhang, Y. PNIPAM microgels for biomedical applications: from dispersed particles to 3D assemblies. Soft Matter 2011, 7 (14), 6375-6384.

7. Ashraf, S.; Park, H.-K.; Park, H.; Lee, S.-H. Snapshot of phase transition in thermoresponsive hydrogel PNIPAM: Role in drug delivery and tissue engineering. Macromolecular Research 2016, 24 (4), 297-304.

8. Ramos, J.; Imaz, A.; Forcada, J. Temperature-sensitive nanogels: poly (Nvinylcaprolactam) versus poly (N-isopropylacrylamide). Polymer Chemistry 2012, 3 (4), 852856.

9. Okada, Y.; Tanaka, F. Cooperative hydration, chain collapse, and flat LCST behavior in aqueous poly (N-isopropylacrylamide) solutions. Macromolecules 2005, 38 (10), 44654471.

10. Bischofberger, I.; Calzolari, D.; De Los Rios, P.; Jelezarov, I.; Trappe, V. Hydrophobic hydration of poly-N-isopropyl acrylamide: a matter of the mean energetic state of water. Scientific reports 2014, 4.

11. Bischofberger, I.; Trappe, V. New aspects in the phase behaviour of poly-N-isopropyl acrylamide: systematic temperature dependent shrinking of PNiPAM assemblies well beyond the LCST. Scientific reports 2015, 5.

12. Hofmeister, F. Zur lehre von der wirkung der salze. Naunyn-Schmiedeberg's Archives of Pharmacology 1888, 25 (1), 1-30.

13. Zhang, Y.; Furyk, S.; Bergbreiter, D. E.; Cremer, P. S. Specific ion effects on the water solubility of macromolecules: PNIPAM and the Hofmeister series. Journal of the American Chemical Society 2005, 127 (41), 14505-14510.

14. Humphreys, B. A.; Willott, J. D.; Murdoch, T. J.; Webber, G. B.; Wanless, E. J. Specific ion modulated thermoresponse of poly (N-isopropylacrylamide) brushes. Physical Chemistry Chemical Physics 2016, 18 (8), 6037-6046.

15. Murdoch, T. J.; Humphreys, B. A.; Willott, J. D.; Gregory, K. P.; Prescott, S. W.; Nelson, A.; Wanless, E. J.; Webber, G. B. Specific Anion Effects on the Internal Structure of a Poly (N-isopropylacrylamide) Brush. Macromolecules 2016, 49 (16), 6050-6060. 
16. Song, J.; Kang, T. H.; Kim, M. W.; Han, S. Ion specific effects: decoupling ion-ion and ion-water interactions. Physical Chemistry Chemical Physics 2015, 17 (13), 8306-8322.

17. Pollard, T. P.; Beck, T. L. Toward a quantitative theory of Hofmeister phenomena: From quantum effects to thermodynamics. Current Opinion in Colloid \& Interface Science 2016, 23, 110-118.

18. Marcus, Y. Specific ion effects on the surface tension and surface potential of aqueous electrolytes. Current Opinion in Colloid \& Interface Science 2016, 23, 94-99.

19. Zhang, Y.; Cremer, P. S. Chemistry of Hofmeister anions and osmolytes. Annual review of physical chemistry 2010, 61, 63-83.

20. Heyda, J.; Dzubiella, J. Thermodynamic description of Hofmeister effects on the LCST of thermosensitive polymers. The Journal of Physical Chemistry B 2014, 118 (37), 1097910988.

21. Record, M. T.; Guinn, E.; Pegram, L.; Capp, M. Introductory lecture: interpreting and predicting Hofmeister salt ion and solute effects on biopolymer and model processes using the solute partitioning model. Faraday discussions 2013, 160, 9-44.

22. Thormann, E. On understanding of the Hofmeister effect: how addition of salt alters the stability of temperature responsive polymers in aqueous solutions. Rsc Advances 2012, 2 (22), 8297-8305.

23. Moghaddam, S. Z.; Thormann, E. Hofmeister effect on thermo-responsive poly (propylene oxide): Role of polymer molecular weight and concentration. Journal of colloid and interface science 2016, 465, 67-75.

24. Moghaddam, S. Z.; Thormann, E. Hofmeister effect on thermo-responsive poly (propylene oxide) in H $2 \mathrm{O}$ and D 2 O. Rsc Advances 2016, 6 (33), 27969-27973.

25. Zhang, Y.; Furyk, S.; Sagle, L. B.; Cho, Y.; Bergbreiter, D. E.; Cremer, P. S. Effects of Hofmeister anions on the LCST of PNIPAM as a function of molecular weight. The Journal of Physical Chemistry C 2007, 111 (25), 8916-8924.

26. Kunz, W.; Nostro, P. L.; Ninham, B. W. The present state of affairs with Hofmeister effects. Current Opinion in Colloid \& Interface Science 2004, 9 (1), 1-18.

27. Pegram, L. M.; Record Jr, M. T. Thermodynamic origin of Hofmeister ion effects. The Journal of Physical Chemistry B 2008, 112 (31), 9428-9436.

28. Gokarn, Y. R.; Fesinmeyer, R. M.; Saluja, A.; Razinkov, V.; Chase, S. F.; Laue, T. M.; Brems, D. N. Effective charge measurements reveal selective and preferential accumulation of anions, but not cations, at the protein surface in dilute salt solutions. Protein Science 2011, 20 (3), 580-587.

29. Gibb, C. L.; Gibb, B. C. Anion binding to hydrophobic concavity is central to the salting-in effects of Hofmeister chaotropes. Journal of the American Chemical Society 2011, 133 (19), 7344-7347.

30. Rembert, K. B.; Okur, H. I.; Hilty, C.; Cremer, P. S. An NH Moiety Is Not Required for Anion Binding to Amides in Aqueous Solution. Langmuir 2015, 31 (11), 3459-3464.

31. Kunz, W.; Belloni, L.; Bernard, O.; Ninham, B. W. Osmotic coefficients and surface tensions of aqueous electrolyte solutions: role of dispersion forces. The Journal of Physical Chemistry B 2004, 108 (7), 2398-2404.

32. Lo Nostro, P.; Ninham, B. W. Hofmeister phenomena: an update on ion specificity in biology. Chemical reviews 2012, 112 (4), 2286-2322.

33. Rembert, K. B.; Paterová, J.; Heyda, J.; Hilty, C.; Jungwirth, P.; Cremer, P. S. Molecular mechanisms of ion-specific effects on proteins. Journal of the American Chemical Society 2012, 134 (24), 10039-10046.

34. Collins, K. D. Why continuum electrostatics theories cannot explain biological structure, polyelectrolytes or ionic strength effects in ion-protein interactions. Biophysical chemistry 2012, 167, 43-59. 
35. Kou, R.; Zhang, J.; Wang, T.; Liu, G. Interactions between Polyelectrolyte Brushes and Hofmeister Ions: Chaotropes versus Kosmotropes. Langmuir 2015, 31 (38), 10461-10468.

36. Irigoyen, J.; Moya, S.; Iturri, J.; Llarena, I.; Azzaroni, O.; Donath, E. Specific לpotential response of layer-by-layer coated colloidal particles triggered by polyelectrolyte ion interactions. Langmuir 2009, 25 (6), 3374-3380.

37. Sokkalingam, P.; Shraberg, J.; Rick, S. W.; Gibb, B. C. Binding Hydrated Anions with Hydrophobic Pockets. Journal of the American Chemical Society 2015, 138 (1), 48-51.

38. Oku, N.; MacDonald, R. C. Solubilization of phospholipids by chaotropic ion solutions. Journal of Biological Chemistry 1983, 258 (14), 8733-8738.

39. Hanstein, W. G. Chaotropic ions and their interactions with proteins. Applied Biochemistry and Biotechnology 1979, 4 (3), 189-206.

40. Hassan, P. A.; Rana, S.; Verma, G. Making sense of brownian motion: colloid characterization by dynamic light scattering. Langmuir 2014, 31 (1), 3-12.

41. Sader, J. E.; Chon, J. W.; Mulvaney, P. Calibration of rectangular atomic force microscope cantilevers. Review of Scientific Instruments 1999, 70 (10), 3967-3969.

42. Ducker, W. A.; Senden, T. J.; Pashley, R. M. Direct measurement of colloidal forces using an atomic force microscope. 1991.

43. Ducker, W. A.; Senden, T. J.; Pashley, R. M. Measurement of forces in liquids using a force microscope. Langmuir 1992, 8 (7), 1831-1836.

44. Xue, Y.; Li, X.; Li, H.; Zhang, W. Quantifying thiol-gold interactions towards the efficient strength control. Nature communications 2014, 5 .

45. Chan, D. Y.; Horn, R. The drainage of thin liquid films between solid surfaces. The Journal of chemical physics 1985, 83 (10), 5311-5324.

46. Thormann, E.; Pettersson, T.; Claesson, P. M. How to measure forces with atomic force microscopy without significant influence from nonlinear optical lever sensitivity. Review of Scientific Instruments 2009, 80 (9), 093701.

47. Deshmukh, S. A.; Sankaranarayanan, S. K.; Suthar, K.; Mancini, D. C. Role of solvation dynamics and local ordering of water in inducing conformational transitions in poly (N-isopropylacrylamide) oligomers through the LCST. The Journal of Physical Chemistry B 2012, 116 (9), 2651-2663.

48. Philipp, M.; Kyriakos, K.; Silvi, L.; Lohstroh, W.; Petry, W.; Krüger, J. K.; Papadakis, C. M.; Müller-Buschbaum, P. From molecular dehydration to excess volumes of phaseseparating PNIPAM solutions. The Journal of Physical Chemistry B 2014, 118 (15), 42534260.

49. Schmidt, S.; Zeiser, M.; Hellweg, T.; Duschl, C.; Fery, A.; Möhwald, H. Adhesion and mechanical properties of PNIPAM microgel films and their potential use as switchable cell culture substrates. Advanced Functional Materials 2010, 20 (19), 3235-3243.

50. Burmistrova, A.; Steitz, R.; von Klitzing, R. Temperature response of PNIPAM derivatives at planar surfaces: Comparison between polyelectrolyte multilayers and adsorbed microgels. ChemPhysChem 2010, 11 (17), 3571-3579.

51. Pelton, R. Poly (N-isopropylacrylamide)(PNIPAM) is never hydrophobic. Journal of colloid and interface science 2010, 348 (2), 673-674.

52. Heskins, M.; Guillet, J. E. Solution properties of poly (N-isopropylacrylamide). Journal of Macromolecular Science-Chemistry 1968, 2 (8), 1441-1455.

53. Mancera, R. L. Influence of salt on hydrophobic effects: A molecular dynamics study using the modified hydration-shell hydrogen-bond model. The Journal of Physical Chemistry B 1999, 103 (18), 3774-3777.

54. Athawale, M. V.; Sarupria, S.; Garde, S. Enthalpy-entropy contributions to salt and osmolyte effects on molecular-scale hydrophobic hydration and interactions. The Journal of Physical Chemistry B 2008, 112 (18), 5661-5670. 
55. Zangi, R.; Hagen, M.; Berne, B. Effect of ions on the hydrophobic interaction between two plates. Journal of the American Chemical Society 2007, 129 (15), 4678-4686.

56. Smith, P. E. Computer simulation of cosolvent effects on hydrophobic hydration. The Journal of Physical Chemistry B 1999, 103 (3), 525-534.

57. HAMANO, K. K. K.; KUWAHARA, N.; FUJISHIGE, S.; ANDO, I. Characterization of poly (N-isopropylmethacrylamide) in water. Polymer journal 1990, 22 (12), 1051-1057.

58. Kujawa, P.; Aseyev, V.; Tenhu, H.; Winnik, F. M. Temperature-sensitive properties of poly ( $\mathrm{N}$-isopropylacrylamide) mesoglobules formed in dilute aqueous solutions heated above their demixing point. Macromolecules 2006, 39 (22), 7686-7693.

59. Zhang, G.; Wu, C. Folding and formation of mesoglobules in dilute copolymer solutions. In Conformation-Dependent Design of Sequences in Copolymers I; Springer, 2006, pp 101-176.

60. Aseyev, V.; Hietala, S.; Laukkanen, A.; Nuopponen, M.; Confortini, O.; Du Prez, F. E.; Tenhu, H. Mesoglobules of thermoresponsive polymers in dilute aqueous solutions above the LCST. Polymer 2005, 46 (18), 7118-7131.

61. Plunkett, M. A.; Claesson, P. M.; Ernstsson, M.; Rutland, M. W. Comparison of the adsorption of different charge density polyelectrolytes: a quartz crystal microbalance and Xray photoelectron spectroscopy study. Langmuir 2003, 19 (11), 4673-4681.

62. Plunkett, M. A.; Claesson, P. M.; Rutland, M. W. Adsorption of a cationic polyelectrolyte followed by surfactant-induced swelling, studied with a quartz crystal microbalance. Langmuir 2002, 18 (4), 1274-1280.

63. Ishida, N.; Biggs, S. Direct Observation of the Phase Transition for a Poly (Nisopropylacryamide) Layer Grafted onto a Solid Surface by AFM and QCM-D. Langmuir 2007, 23 (22), 11083-11088.

64. Annaka, M.; Yahiro, C.; Nagase, K.; Kikuchi, A.; Okano, T. Real-time observation of coil-to-globule transition in thermosensitive poly (N-isopropylacrylamide) brushes by quartz crystal microbalance. Polymer 2007, 48 (19), 5713-5720.

65. Laloyaux, X.; Mathy, B.; Nysten, B.; Jonas, A. M. Surface and bulk collapse transitions of thermoresponsive polymer brushes. Langmuir 2009, 26 (2), 838-847.

66. Cappella, B. Physical Principles of Force-Distance Curves by Atomic Force Microscopy. In Mechanical Properties of Polymers Measured through AFM Force-Distance Curves; Springer, 2016, pp 3-66.

67. Goodman, D.; Kizhakkedathu, J. N.; Brooks, D. E. Attractive bridging interactions in dense polymer brushes in good solvent measured by atomic force microscopy. Langmuir 2004, $20(6), 2333-2340$.

68. Sui, X.; Zapotoczny, S.; Benetti, E. M.; Schön, P.; Vancso, G. J. Characterization and molecular engineering of surface-grafted polymer brushes across the length scales by atomic force microscopy. Journal of Materials Chemistry 2010, 20 (24), 4981-4993.

69. Malham, I. B.; Bureau, L. Density effects on collapse, compression, and adhesion of thermoresponsive polymer brushes. Langmuir 2009, 26 (7), 4762-4768.

70. Thormann, E.; Simonsen, A. C.; Hansen, P. L.; Mouritsen, O. G. Interactions between a polystyrene particle and hydrophilic and hydrophobic surfaces in aqueous solutions. Langmuir 2008, 24 (14), 7278-7284.

71. Olanya, G.; Thormann, E.; Varga, I.; Makuška, R.; Claesson, P. M. Protein interactions with bottle-brush polymer layers: Effect of side chain and charge density ratio probed by QCM$\mathrm{D}$ and AFM. Journal of colloid and interface science 2010, 349 (1), 265-274.

72. Thormann, E.; Bodvik, R.; Karlson, L.; Claesson, P. M. Surface forces and friction between non-polar surfaces coated by temperature-responsive methylcellulose. Colloids and Surfaces A: Physicochemical and Engineering Aspects 2014, 441, 701-708. 
73. Fleer, G.; Stuart, M. C.; Scheutjens, J.; Cosgrove, T.; Vincent, B. Polymers at interfaces; Springer Science \& Business Media1993.

74. Butt, H.-J. Measuring electrostatic, van der Waals, and hydration forces in electrolyte solutions with an atomic force microscope. Biophysical journal 1991, 60 (6), 1438-1444.

75. Thormann, E. Surface forces between rough and topographically structured interfaces. Current Opinion in Colloid \& Interface Science 2017, 27, 18-24.

76. Furusawa, H.; Sekine, T.; Ozeki, T. Hydration and Viscoelastic Properties of High-and Low-Density Polymer Brushes Using a Quartz-Crystal Microbalance Based on Admittance Analysis (QCM-A). Macromolecules 2016, 49 (9), 3463-3470.

77. Kubota, K.; Fujishige, S.; Ando, I. Solution properties of poly (N-isopropylacrylamide) in water. Polym. J 1990, 22 (1), 15-20.

78. Heyda, J.; Muzdalo, A.; Dzubiella, J. Rationalizing polymer swelling and collapse under attractive cosolvent conditions. Macromolecules 2013, 46 (3), 1231-1238.

79. Crevenna, A. H.; Naredi-Rainer, N.; Lamb, D. C.; Wedlich-Söldner, R.; Dzubiella, J. Effects of Hofmeister ions on the $\alpha$-helical structure of proteins. Biophysical journal 2012, 102 (4), 907-915.

80. Heyda, J.; Okur, H. I.; Hladílková, J.; Rembert, K. B.; Hunn, W.; Yang, T.; Dzubiella, J.; Jungwirth, P.; Cremer, P. S. Guanidinium can both Cause and Prevent the Hydrophobic Collapse of Biomacromolecules. Journal of the American Chemical Society 2017. 